\title{
STUDY ON SPATIAL CULTURAL HERITAGE INTEGRATED INTO THE CORE CURRICULUM
}

\author{
Wen-Huay Hsu ${ }^{\mathrm{a}}$,Yu-Peng Lai ${ }^{\mathrm{b}}$ \\ ${ }^{a}$ Dept. of Construction and Spatial Design, Tungnan University, No.152, Section 3, Beishen Rd., Shenkeng Dist., New Taipei City \\ 22202, Taiwan - xwh.dn@mail.tnu.edu.tw \\ ${ }^{\mathrm{b}}$ Dept. of Construction and Spatial Design, Tungnan University - yupeng@ mail.tnu.edu.tw
}

KEY WORDS: Spatial Cultural Heritage, Core Curriculum, Tungnan University, Shenkeng Historic Cultural District,

\begin{abstract}
:
These Many countries have put a lot of efforts, promoting education of cultural heritage, to raise the conservation awareness and increase people's participation. However, the development of Taiwan's higher education about cultural heritage has not shown a significant growth, so it didn't train talents with enough cultural heritage awareness. In the workplace, these professionals will inevitably lack of comprehensions and the appropriate professional assessments for cultural heritage. Hence, the main objective of this paper is to study and combine these concepts into the core curriculum of Department of Construction and Spatial Design at Tungnan University. It takes the local " Shenkeng historic cultural district " as a case study, and will gradually develop an proper interdisciplinary course in order to help local residents implement projects of conserving cultural heritage. This plan not only can increase schools' engagements toward communities, with an ability of social civilization, but also it can encourage the conservation and maintenance of cultural heritages.
\end{abstract}

\section{RESEARCH MOTIVE AND PURPOSE}

Conserving cultural heritage to pass to our next generation is an international trend now. It is undeniable that many factors from cultural, academic, educational, political, and economic influence its results. (Chen, 1986). Therefore, many countries have put a lot of efforts to promote relevant programs which particularly emphasize on higher education of cultural heritage, and especially focus on raising the conservation awareness. The higher education of conservation for cultural heritages in Taiwan has been developed more than twenty years. However, we still don't have enough trained professionals. Although the reservation and repairing work for monuments and historic buildings are continuously growing, these related professionals on the job market are still lack of deep comprehensions and professional assessments on preservations of historic buildings. Neither public sector nor the public fully realize the necessity to maintain these traditional buildings which seems outdated in compare with the modern design. Thus, it is necessary for the public to establish the correct concept of conservation, and more urgent to enhance this on our educational systems.

Tungnan University is located at Shenkeng historic cultural district in New Taipei City, a region with rich cultural heritages, as well as a main place for students' activities. However, most of the students do not know much about the local history, culture and environment, and only view it as a place for sightseeing and leisure. At same time, it is a pity that schools do not have any plan involving local history and culture to educate students what to understand or how to decide what "Shenkeng cultural heritages" is.

The cultural heritages owned by locals are the most precious "Collective Memory" shared among them. But if there is no volunteering organization leads the activities to promote the "Region Identity", it is very difficult for locals to develop it. In addition, the government has not yet established a complete local database, so it is also difficult to pass down the past experiences with preservation, maintenance or management to next generation, and further, combine the cultural heritage with the local life. To make up this gap, this paper aims to take the Department of Construction and Spatial Design (abbr. DCSD) at Tungnan University as the main research subject, to redesign its core class curriculum, so that teaching can be fully combined with local cultural heritages. There are the following three goals:

1. Educate students to gain both an international perspective and historic literacy of local cultures in order to achieve a comprehensive promotion for preservation awareness of cultural heritage.

2. Utilize the local resources, to narrow the gap between students' learning and their applications in industry.

3. Take university as a communication media between local residents and students, and invite locals to participate in the design of historic district.

\section{OBJECTIVES OF RESEARCH}

\subsection{Research Topics}

This paper aims to study a feasibility of combining the professional knowledge and technical capability for the spatial cultural heritage preservation from the core curriculum. We intend to research surroundings of monuments, historical buildings, settlements and cultural landscapes, and use this as special a characteristics for the course at the same

\footnotetext{
* Corresponding author
} 
time. ${ }^{1}$ Especially, when these cultural heritages could be viewed as a real contactable teaching tools, this is very worth studying further and has a unique meaning and value.

\subsection{Research Subject- Shenkeng Historic Cultural District}

Tungnan University is located in New Taipei City, close to Shenkeng historic cultural district (Figure 1). Fortunately, this region is not only one of major places for many students' activities, and local cultural ones for historical buildings, but also can be used as a rich and clear example to enhance teachers' and students' learning. Because common life experience is the most efficient teaching tool, it is the easiest way for students to understand the cultural resources. Based on this, the paper takes " Shenkeng historic cultural district " as a research subject.

At the late time of Qing Dynasty, many Fujian immigrants came here to reclaim. Because both transportations by land and water were very convenient at that time, agricultural products and groceries not only could be distributed here, but also could bring in a rich locally architectural features and cultural resources. Shenkeng historical street was the historic district of traditional business culture. It has developed a unique shape of street with narrow width and long depth, namely "long townhouse" group. In 1915, the Japanese colonial government under "Urban Implementation Plan" widened the road and built a high bricked based arcade arches, that formed the basic style of street blocks for today. In order to solve the old buildings problem in the historic district, the local government began its renovation in 2008 and was roughly completed until 2012.

In addition, "Huang's courtyard houses" is the largest and most representative historic home ${ }^{2}$ that has a total seven groups of residential buildings. ${ }^{3}$ It was rare in Taiwan to build settlements with the same family name, and each residential group was interspersed between villages. Among them, Yongan Ancestral House has been recognized as Third monuments in 1992 and was listed as one of Taiwan's top ten historic homes. From designs, layouts or styles, they all inherited Quanzhou architectural style.

\subsection{Core Courses of Research}

This paper studies the core courses in DCSD at Tungnan University which consists of two major professional directions: "green construction design " and "spatial design".

1 According to the latest amendments released (effective November 9, 2011) " Cultural Heritage Preservation Act " Article 3.1'Monuments, Historical Buildings and Settlements: the buildings and/or ancillary facilities built for the needs of human life with historic and/or cultural value.' , and Article 3.3-' Cultural Landscapes: the location or environment which is related to any myths, legends, record of events, historical events, social life or ceremonies.'

2 "Shenkeng Township Gazetteer" Culture chapter, the monuments in Shenkeng contain four types: tea road, forest of steles, historic home, and legend.

3 According to the field study, "Huang's courtyard houses" have seven residential group included Huang's Founding Ancestral House, Huang Lian-Shan's Ancestral House, Fuan Ancestral House, Yongan Ancestral House, Xingshun Ancestral House, Rungde Ancestral House, Sixth Son Ancestral House (sixth son of Huang Lian-Shan).

\section{CULTURAL HERITAGE EDUCATION AT THE VOCATIONAL UNIVERSITIES}

Cultural heritage higher education in Taiwan has been developed for more than twenty years. However, it is still considered a non-mainstream education. Currently, owing to the change of the industry needs and the trend of fewer students, school has renamed cultural assets department or changed the original curriculum organization. The technical education systems emphasize the direct connections to the professional workplace, so that it is easy to ignore this important issue about cultural heritage. Although many educators recognize its importance and necessity, very few people has taken any action.

After analyzing the relevant departments in all vocational universities, they can be divided into two types. The traditional type has course assignment at Department of Cultural Heritage Conservation, Department of Architecture, or Department of Anthropology. The other follows the cultural and recreation trends to establish a new department with the name of cultural tourism, cultural development. Most schools merely mention the cultural heritage concept in their common course, so student's the conservation awareness and participations to preserve cultural heritages are usually low, and they don't seem to care.

Moreover, the cultural heritage is a interdisciplinary study, including urban design, architectural design, regulation, management, and marketing information, this is difficult for students to get enough training in only one field. Besides, the teaching must go beyond history education's nostalgia thinking, and emphasize the rational discourse ( Fu, 2014).

In short, it is necessary for "relevant departments" to explore a feasible and effective approach concerning promoting the culture heritage education. This allows students to identify the preservation of cultural heritage, affecting the locals to enhance the cultural value existed in the region.

\section{DESIGN OF CORE COURSES}

The Spatial cultural heritages (monuments, historic buildings, settlements and cultural landscapes) are the tangible spatial entities, those are full of rich cultural, educational, historical facts, aesthetic, emotional, economic values and so on. DCSD contains exactly this diverse, professional and interdisciplinary characteristic. In other words, the knowledge and records of cultural heritage can be integrated into this curriculum. Not only courses can utilize the historic and cultural resources in Shenkeng district, but also can encourage students to participate in issues of cultural heritage, and then schools play an active role in the communities. Meanwhile, from the view of the job prospective, students have an opportunity to become the potential professionals.

Therefore, under the framework of core curriculum, on one hand we can increase elective courses for students to establish the basic concepts and knowledge. On the other hand we can expand the content of required courses for students to learn the implicational knowledge of cultural heritage, and in practical courses give them opportunities to collaborate (Figure 2). 


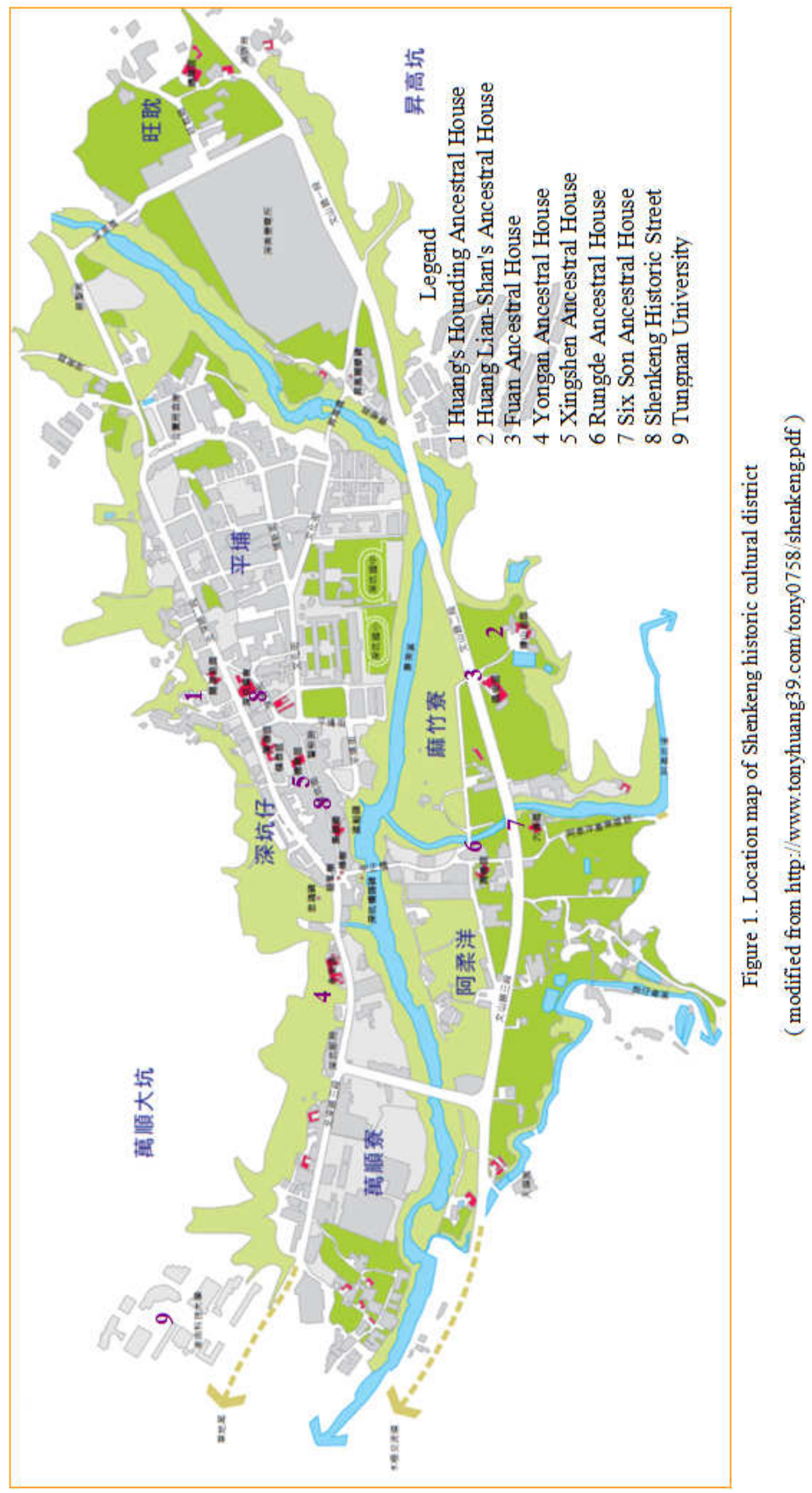




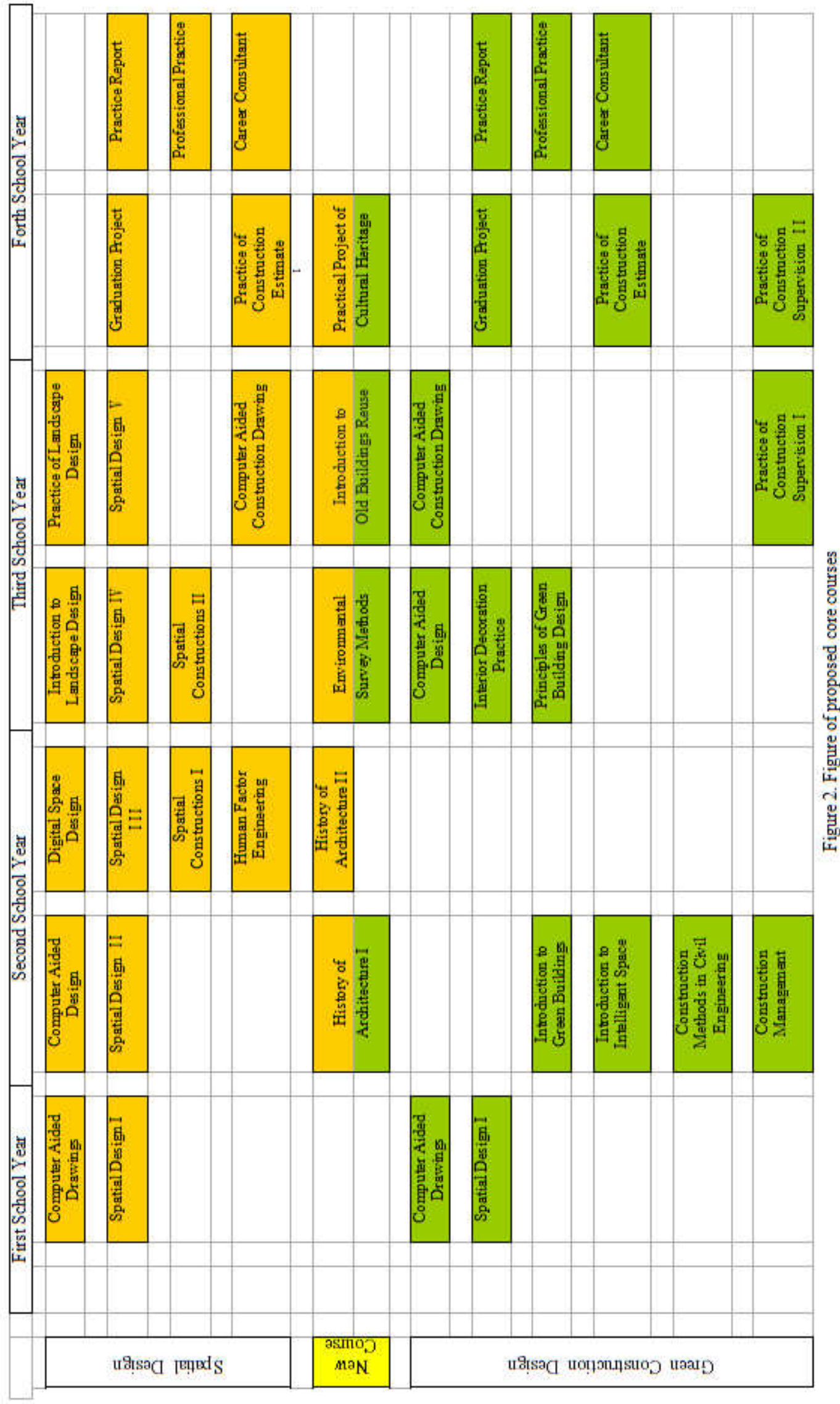




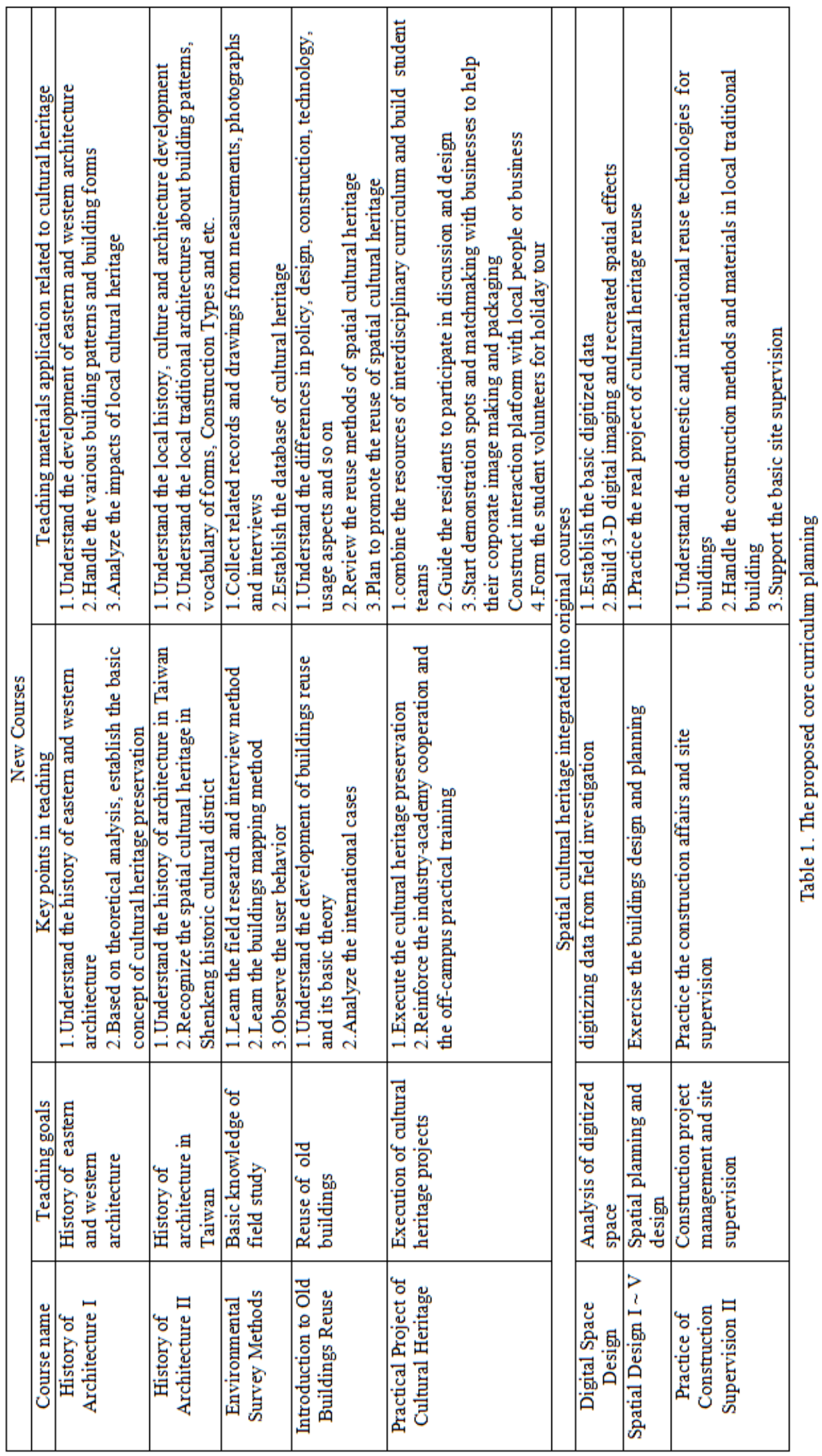


Thus, the main promoting plan for this project is to take Shenkeng district as major place for activities, and initiate the research, record, planning and redesign of spatial cultural heritages (Table 1). The former will increase five new courses, including " History of Architecture I ", " History of Architecture II ", " Environmental Survey Methods ", "Introduction to Old Buildings Reuse ", " Practical Project of Cultural Heritage ", the latter will enrich existing courses, mainly including " Digital Space Design ", " Spatial Design I V ", " Practice of Construction Supervision II ". Department should develop this course proposals year by year, in order to avoid affecting the original teaching focuses, meanwhile, through the early experimental stage course contents could constantly be revised to sort out a consensus for teaching approach. In other words, teaching students to have the basic knowledge of cultural heritage preservation, or helping locals further to maintain historic buildings and sustain cultural identity, curriculum plan is able to combine theory and practice.

\section{CONCLUSION}

Different professions should all follow the world trend to include awareness of the cultural heritage preservation as well as to enhance regional identity. Therefore, besides the goal of " professional knowledge " and " practical experience ", technological and vocational higher education should increase observational ability for contemporary cultural heritage issues. By conducting cultural literacy, school education could adjust teaching environments. Based on this case study, the expected effects are listed as followings. First, this proposed courses program would develop teaching materials, and increase diversity of professional training. Second of all, it would educate local residents to respect cultural heritage, and revitalize regional historic space, which could instil students the idea of giving back to the community. Finally, it would help to build local culture heritage database.

Redesigning school education is only the initial step to promote preservation of cultural heritage. In the future, there should be many complete packages of professional courses to let potential talents show their strengths. Moreover, these people could not only participate in the conservation of local monuments and historic buildings, but also provide a new concept for preservation of cultural heritage, which would make the city development has cultural characteristic.

\section{REFERENCES}

Chen, Yi-Chao. 1986. Conservation and Maintenance of Cultural Heritage. Taipei, Council for Cultural Affairs, Executive Yuan.

Lin, Neng-shi. 1997. Shenkeng Township Gazetteer. New Taipei City: Shenkeng Township Office.

Fu, Chao-Ching. (2014): Establish more critical education for space class cultural heritage in Taiwan. ARCHITECURAL INSTITUTE OF TAIWAN MAGAZINE, Issue76, pp.7-12.

http://www.tonyhuang39.com/tony0758/shenkeng.pdf 